\title{
Analysis of long-term (median 10.5 years) outcomes in children presenting with traumatic brain injury and an initial Glasgow Coma Scale score of 3 or 4
}

\author{
Daniel H. Fulkerson, MD, ${ }^{1}$ lan K. White, MD, ${ }^{2}$ Jacqueline M. Rees, MD, ${ }^{2}$ Maraya M. Baumanis, BS, ${ }^{2}$ \\ Jodi L. Smith, PhD, MD,1 Laurie L. Ackerman, MD,1 Joel C. Boaz, MD,1 and \\ Thomas G. Luerssen, MD³
}

\begin{abstract}
1Department of Neurological Surgery, Division of Pediatric Neurosurgery, Goodman Campbell Brain and Spine; ${ }^{2}$ Department of Neurological Surgery, Indiana University School of Medicine, Indianapolis, Indiana; and 'Department of Neurological Surgery, Baylor College of Medicine, Texas Children's Hospital, Pediatric Neurosurgery, Houston, Texas
\end{abstract}

\begin{abstract}
OBJECT Patients with traumatic brain injury (TBI) with low presenting Glasgow Coma Scale (GCS) scores have very high morbidity and mortality rates. Neurosurgeons may be faced with difficult decisions in managing the most severely injured (GCS scores of 3 or 4) patients. The situation may be considered hopeless, with little chance of a functional recovery. Long-term data are limited regarding the clinical outcome of children with severe head injury. The authors evaluate predictor variables and the clinical outcomes at discharge, 1 year, and long term (median 10.5 years) in a cohort of children with TBI presenting with postresuscitation GCS scores of 3 and 4.
\end{abstract}

METHODS A review of a prospectively collected trauma database was performed. Patients treated at Riley Hospital for Children (Indianapolis, Indiana) from 1988 to 2004 were reviewed. All children with initial GCS (modified for pediatric patients) scores of 3 or 4 were identified. Patients with a GCS score of 3 were compared with those with a GCS score of 4. The outcomes of all patients at the time of death or discharge and at 1-year and long-term follow-up were measured with a modified Glasgow Outcome Scale (GOS) that included a "normal" outcome. Long-term outcomes were evaluated by contacting surviving patients. Statistical "classification trees" were formed for survival and outcome, based on predictor variables.

RESULTS Sixty-seven patients with a GCS score of 3 or 4 were identified in a database of 1636 patients (4.1\%). Three of the presenting factors differed between the GCS 3 patients $(n=44)$ and the GCS 4 patients $(n=23)$ : presence of hypoxia, single seizure, and open basilar cisterns on CT scan. The clinical outcomes were statistically similar between the 2 groups. In total, $48(71.6 \%)$ of 67 patients died, remained vegetative, or were severely disabled by 1 year. Eight patients $(11.9 \%)$ were normal at 1 year. Ten of the 22 patients with long-term follow-up were either normal or had a GOS score of 5 . Multiple clinical, historical, and radiological factors were analyzed for correlation with survival and clinical outcome. Classification trees were formed to stratify predictive factors. The pupillary response was the factor most predictive of both survival and outcome. Other factors that either positively or negatively correlated with survival included hypothermia, mechanism of injury (abuse), hypotension, major concurrent symptoms, and midline shift on CT scan. Other factors that either positively or negatively predicted long-term outcome included hypothermia, mechanism of injury, and the assessment of the fontanelle.

CONCLUSIONS In this cohort of 67 TBI patients with a presenting GCS score of 3 or $4,56.6 \%$ died within 1 year. However, approximately $15 \%$ of patients had a good outcome at 10 or more years. Factors that correlated with survival and outcome included the pupillary response, hypothermia, and mechanism. The authors discuss factors that may help surgeons make critical decisions regarding their most serious pediatric trauma patients.

http://thejns.org/doi/abs/10.3171/2015.3.PEDS14679

KEY WORDS traumatic brain injury; pediatric; Glasgow Coma Scale; Glasgow Outcome Scale; trauma

ABBREVIATIONS GCS = Glasgow Coma Scale; GOS = Glasgow Outcome Scale; ICP = intracranial pressure; TBI = traumatic brain injury. SUBMITTED December 2, 2014. ACCEPTED March 16, 2015.

INCLUDE WHEN CITING Published online July 3, 2015; DOI: 10.3171/2015.3.PEDS14679.

DISCLOSURE Funding for the statistical analysis was provided by the Goodman Campbell Foundation. 
$\mathrm{T}$ Raumatic brain injury (TBI) is a leading cause of death and morbidity in pediatric patients. Approximately 1.5 million people in the United States suffer TBI annually, resulting in an estimated 50,000 deaths and 500,000 patients with permanent disability. ${ }^{44,49}$ The Glasgow Coma Scale (GCS) score is a well-accepted measure of the severity of the injury. ${ }^{47}$ There are modifications of the adult GCS for children. ${ }^{27,42,46}$ Adult patients with a GCS score of $\leq 8$ are considered to have "severe" TBI. In children, a GCS score of 5 may be the critical level for "severe" TBI. ${ }^{10}$ In both adults and children, patients with a GCS score of 3 or 4 have the most severe injuries.

Clinicians may have a justifiably pessimistic view regarding these patients, because survival may be considered unlikely. Even if the patient survives the initial injury, the chance for meaningful neurological function may be poor. One may question the logic of committing significant resources to a patient if the outcome is likely to be death or vegetative survival. The difficulty of addressing these ethical concerns may be magnified in cases involving children, especially those who have suffered abuse.

To make decisions in the acute phase of treatment, we feel long-term data on the outcomes of these critically ill patients are crucial. There are very few studies that follow pediatric TBI patients for longer than 1 year. The neurosurgical service at Riley Hospital for Children (Indianapolis, Indiana) maintained a prospective database of all head-injured patients from 1988 to 2004. We evaluated all patients who presented with a GCS score of 3 or 4 . Outcomes were evaluated at discharge, 1 year, and long term. Long-term (median 10.5 years, mean $11.04 \pm 6.1$ years) outcomes were evaluated by contacting survivors. Clinical, historical, and radiological factors were statistically correlated to survival and clinical outcome.

\section{Methods}

The neurosurgical service at Riley Hospital for Children, a Level 1 pediatric trauma center, maintained a database of all head-injured patients from 1988 to 2004. Scores were recorded for the modified pediatric GCS ${ }^{32,46}$ (also referred to simply as "GCS" in discussions of pediatric patients). All patients who presented with a GCS score of 3 or 4 were identified. The project began after local institutional review board approval.

The database was prospectively maintained by the neurosurgical service during the inclusive years. A neurosurgical research nurse recorded admission, hospital, and discharge information. Epidemiological data points included patient age at injury, sex, race, method of transport, mechanism of injury, and the possibility of abuse/ nonaccidental trauma. Patients involved in a motor vehicle accident were subdivided according to accident characteristics: pedestrian, biker (fall, struck by vehicle, presence of helmet), and passenger (restrained vs not restrained). Clinical data points included presence of one or multiple seizures, responsiveness at the scene, and intubation at the scene versus in hospital. Physical examination findings included lowest systolic blood pressure, temperature, left and right pupil size, presence of retinal hemorrhages, and evaluation of the anterior fontanelle (if patent). "Hypother- mia" was defined as a recorded initial temperature of less than $36^{\circ} \mathrm{C}$. A patient was considered to be "hypotensive" if their lowest recorded systolic blood pressure was less than 2 standard deviations of the normal for age. The modified pediatric GCS score was recorded by the examining neurosurgeon (either the resident or attending physician). Every effort was made to record this score with the patient adequately resuscitated and free of sedating medications.

Radiological factors recorded from the initial CT scan included skull fracture (including size, length, open vs closed, depressed, basilar), hemorrhage/hematoma (intraventricular, intracerebral, subarachnoid, epidural, and subdural), patency or effacement of basilar cisterns, midline shift of $>1 \mathrm{~cm}$, infarction, hydrocephalus, and pneumocephalus. Hospitalization data points included surgery, intracranial pressure (ICP) monitoring or external ventricular drain placement, and evaluation of the immediate outcome. Patient disposition was recorded. Outcomes were recorded at death, discharge, 1 year, and long term ( $>$ 1 year) using a modified version of the Glasgow Outcome Scale (GOS). We modified the GOS to include a category for "normal" as follows: "normal," normal in every respect; 5 , good recovery with minor cognitive or neurological problems; 4, disabled neurologically or cognitively; 3 , severely disabled, possibly requiring institutional care; 2 , vegetative survival; 1 , death.

A normal patient outcome was defined as being neurologically intact, functioning at the appropriate grade level and/or able to graduate from high school, being gainfully employed, and/or living independently. Patients with a GOS score of 5 are able to attend school with minor problems and/or live independently. A score of 4 indicates a patient who is functional and ambulatory but has cognitive problems requiring special education and government assistance, and who is unable to function independently. A score of 3 indicates a patient who has severe neurological defects (such as spastic quadriparesis) and requires full-time care. A score of 2 includes patients with severe deficits who are unable to interact with their environment, requiring complete care.

We used statistical analysis to compare patients with a GCS score of 3 to those with a score of 4 . While there were a few differences in presenting variables, the survival and outcomes at discharge were statistically similar. Therefore, all patients were grouped together to evaluate survival and clinical outcome at 1 year and long term. Long-term data were obtained either from current medical records or by telephone contact.

Statistical analysis was performed using $\mathrm{R}$ software, version 2.13.1. Data were analyzed using the t-test for continuous variables and Fisher exact test for the categorical variables. All of the above clinical, epidemiological, and radiological variables were included in the analysis. Statistical significance was set as $\mathrm{p} \leq 0.05$.

Statistical "classification trees" were formed to predict membership in the class of a categorical dependent variable from 1 or more predictor variables. The classification tree is used to find the optimal way to split data into different classes on the basis of the characteristics of the variables of interest. The Gini rule ${ }^{7}$ was the default quality-ofsplit criterion used in the analysis. The Gini rule is applied 
to determine the largest class in the database and isolate it from all others. It measures how well the "splitting rule" separates the classes contained in the parent node. The tree is built by first identifying the single variable that best splits the data into 2 groups according to the Gini rule. The first selected variable located at the top of the tree provides the split with maximal impurity reduction. Once the data are separated by the first variable, the same splitting process is applied to each subgroup. The process is repeated recursively until the subgroups either reach a minimum size or until no improvement can be made based on the Gini rule. We set the minimum size as 1 .

\section{Results}

Sixty-seven $(4.1 \%)$ of the 1636 patients in the database had a GCS score of 3 or 4 . Of the 67 patients, 44 presented with an initial GCS score of 3 , and 23 patients had a GCS score of 4 . The demographic data are shown in Table 1 . There were no statistically significant differences in the sex, race, age, or mechanism of injury between the patients with GCS 3 or 4 .

The clinical presentations of patients with GCS scores of 3 and those with a score of 4 were compared. The analyzed variables between the 2 groups are shown in Table 2 and are comparable in most respects. However, there was a statistically significant difference in the percentage of presentation between groups for 3 of the variables: presence of hypoxia $(65.9 \%$ of GCS 3 patients vs $39.1 \%$ of GCS 4 patients, $\mathrm{p}=0.046)$; single seizure $(2.3 \%$ of GCS 3 patients vs $17.4 \%$ of GCS 4 patients, $p=0.044$ ); and patent ("open") cisterns on CT scan (68.2\% of GCS 3 patients vs $91.3 \%$ of GCS 4 patients, $\mathrm{p}=0.04$ ).

\section{Survival and Outcomes at Discharge}

The discharge outcomes are shown in Table 3. A total of 37 patients $(55.2 \%)$ died, including 27 patients $(61.4 \%)$ with a GCS score of $3(n=44)$ and 10 patients $(43.5 \%)$ with a GCS score of $4(n=23)$. No patients were classified as normal at discharge. There was no statistically significant difference in survival between patients with GCS scores of 3 and those with GCS scores of $4(p=0.2)$. There was no statistically significant difference in discharge GOS scores $(p=0.447)$ between the 2 groups.

A statistical classification tree was created to predict survival or death (Fig. 1). The most predictive variable was pupillary reaction. If the pupillary reaction in both eyes was normal, the chance of survival was $87 \%$. If the pupillary reaction was abnormal (in one or both eyes), the chance of survival dropped to $23 \%$.

The classification tree was branched further. For those with a normal pupillary reaction, the next most important variable was whether abuse was the mechanism of injury. Patients with reactive pupils who did not suffer abuse had a $100 \%$ survival rate. Patients with reactive pupils and abuse had a 50\% survival rate. For abused patients, the next variable was the presence of hypotension. Patients without hypotension had a $75 \%$ chance of survival, whereas those with hypotension had a $0 \%$ chance.

In patients with an abnormal pupillary response, the next most important variable was the presence of hypo-
TABLE 1. Demographic data of the study group $(n=67)$

\begin{tabular}{|c|c|c|c|}
\hline Patient Characteristics & $\begin{array}{c}\text { GCS Score } 3 \\
(n=44)\end{array}$ & $\begin{array}{c}\text { GCS Score } 4 \\
(n=23)\end{array}$ & p Value ${ }^{*}$ \\
\hline $\begin{array}{l}\text { Sex, n (\%) } \\
\text { M } \\
\text { F }\end{array}$ & $\begin{array}{l}27(61.4) \\
17(38.6)\end{array}$ & $\begin{array}{l}13(56.5) \\
10(43.5)\end{array}$ & 0.792 \\
\hline $\begin{array}{l}\text { Race, } \mathrm{n}(\%) \\
\text { Caucasian } \\
\text { African-American } \\
\text { Hispanic } \\
\text { Other/unknown }\end{array}$ & $\begin{array}{c}34(77.3) \\
6(13.6) \\
1(2.3) \\
3(6.8)\end{array}$ & $\begin{array}{l}11(33.3) \\
6(18.2) \\
2(6.1) \\
4(12.1)\end{array}$ & 0.076 \\
\hline $\begin{array}{l}\text { Age }(\mathrm{mos}) \\
\text { Mean } \pm \text { SD } \\
\text { Range }\end{array}$ & $\begin{array}{c}49.8 \pm 51.8 \\
1 \mathrm{mo}-15.1 \mathrm{yrs}\end{array}$ & $\begin{array}{c}66.9 \pm 58.0 \\
2 \text { mos- }-15.7 \text { yrs }\end{array}$ & 0.2437 \\
\hline $\begin{array}{l}\text { Mechanism of injury, n (\%) } \\
\text { Nonaccidental trauma } \\
\text { Pedestrian struck } \\
\text { Motor vehicle accident } \\
\text { Fall from height } \\
\text { Bicycle fall } \\
\text { Struck by object }\end{array}$ & $\begin{array}{r}23(52.3) \\
9(20.5) \\
7(15.9) \\
3(6.8) \\
1(2.3) \\
1(2.3)\end{array}$ & $\begin{array}{l}7(30.4) \\
5(21.7) \\
4(17.4) \\
3(13.0) \\
3(13.0) \\
1(4.3)\end{array}$ & 0.275 \\
\hline
\end{tabular}

* Fisher exact test.

thermia. A patient with an abnormal pupillary response and hypothermia had a probability of survival of $14 \%$, whereas a patient without hypothermia had a probability of survival of $56 \%$. The remainder of the variables are shown in Fig. 1. The lowest categories are terminal nodes. For example, a child without midline shift on CT, involved in a motor vehicle accident, with hypothermia, and with an abnormal pupillary response had a $0 \%$ chance of survival.

\section{Outcomes at 1 Year and Long Term}

There were 37 initial deaths. One patient died prior to 1 year of follow-up. Therefore, there were a total of 29 potential survivors. The outcomes of 5 patients were unknown or lost to follow-up at 1 year. The outcomes at 1 year are shown in Table 4. Ten patients (14.9\%) had a "normal" or GOS Score 5 outcome. Ten patients (14.9\%) were longterm survivors but had a GOS score of 2 or 3, indicating severe disability or vegetative state. In total, $48(71.6 \%)$ of 67 died, remained vegetative, or were severely disabled.

We attempted to obtain clinical data on all patients known to have survived to 1 year. Two patients had followup data at 1 year, but no data past this time. We were able to obtain data past 1 year in 22 patients. In these patients, the mean follow-up duration was $11.04 \pm 6.1$ years (median 10.5 years). Table 5 shows the long-term data in greater detail. The GOS at 1 year correlated with the long-term GOS, although 1 patient improved. Therefore, 21 (95.5\%) of 22 patients had the same GOS score long term as at 1 year, with 1 patient improving from a GOS score of 2 to 3 (by 7 years). Comments on the subjective quality of life are included in the table.

A classification tree was derived from predictor variables of outcome based on the long-term GOS (Fig. 2). Again, the most important variable was the pupillary reaction. Patients with a normal pupillary reaction had a $27 \%$ 
TABLE 2. Analysis of presenting variables

\begin{tabular}{|c|c|c|c|}
\hline Variable & $\begin{array}{c}\text { GCS Score } 3^{*} \\
(n=44)\end{array}$ & $\begin{array}{l}\text { GCS Score } \\
4^{*}(n=23)\end{array}$ & $\mathrm{p}$ Value \\
\hline $\begin{array}{l}\text { Hypoxia } \\
\text { Yes } \\
\text { No } \\
\text { Unknown/not recorded }\end{array}$ & $\begin{array}{r}29(65.9) \\
8(18.2) \\
7(15.9)\end{array}$ & $\begin{array}{c}9(39.1) \\
4(17.4) \\
10(43.5)\end{array}$ & 0.046 \\
\hline Pupil asymmetry & $9(20.4)$ & $3(13.0)$ & 0.523 \\
\hline $\begin{array}{l}\text { Hypotension } \\
\text { Yes } \\
\text { No } \\
\text { Unknown/not recorded }\end{array}$ & $\begin{array}{l}22(50) \\
16(36.4) \\
6(13.6)\end{array}$ & $\begin{array}{l}8(34.8) \\
7(30.4) \\
8(34.8)\end{array}$ & 0.131 \\
\hline $\begin{array}{l}\text { Hypothermia } \\
\text { Yes } \\
\text { No } \\
\text { Unknown/not recorded }\end{array}$ & $\begin{array}{l}22(50) \\
15(34.1) \\
7(15.9)\end{array}$ & $\begin{array}{l}7(30.4) \\
7(30.4) \\
9(39.1)\end{array}$ & 0.101 \\
\hline $\begin{array}{l}\text { Secondary symptoms } \\
\text { Abdominal injury } \\
\text { Chest trauma } \\
\text { Spinal cord injury } \\
\text { Long bone fractures } \\
\text { Respiratory distress } \\
\text { Seizure (single) } \\
\text { Seizures (multiple) } \\
\text { No additional symptoms }\end{array}$ & $\begin{array}{c}1(2.3) \\
6(13.6) \\
1(2.3) \\
8(18.2) \\
23(52.3) \\
1(2.3) \\
9(20.5) \\
5(11.4)\end{array}$ & $\begin{array}{l}2(8.7) \\
0 \\
0 \\
1(4.3) \\
14(60.9) \\
4(17.4) \\
2(8.7) \\
3(13.0)\end{array}$ & $\begin{array}{c}0.269 \\
0.087 \\
1.000 \\
0.149 \\
0.608 \\
0.044 \\
0.307 \\
>0.99\end{array}$ \\
\hline $\begin{array}{l}\text { Radiographic findings } \\
\text { Skull fracture } \\
\text { Basilar } \\
\text { Open depressed }\end{array}$ & $\begin{array}{l}15(34.1) \\
3(6.8) \\
0\end{array}$ & $\begin{array}{l}8(34.8) \\
2(8.7) \\
1(4.3)\end{array}$ & $\begin{array}{c}>0.99 \\
>0.99 \\
0.343\end{array}$ \\
\hline $\begin{array}{l}\text { Hemorrhage } \\
\text { Intraventricular } \\
\text { Intraparenchymal } \\
\text { Subarachnoid } \\
\text { Subdural } \\
\text { Epidural }\end{array}$ & $\begin{array}{c}8(18.2) \\
7(15.9) \\
31(70.5) \\
29(65.9) \\
1(2.3)\end{array}$ & $\begin{array}{c}3(13.0) \\
5(21.7) \\
15(65.2) \\
15(65.2) \\
1(4.3)\end{array}$ & $\begin{array}{c}0.736 \\
0.738 \\
0.783 \\
>0.99 \\
>0.99\end{array}$ \\
\hline $\begin{array}{l}\text { Cisterns } \\
\text { Open } \\
\text { Compressed }\end{array}$ & $\begin{array}{l}30(68.2) \\
14(31.8)\end{array}$ & $\begin{array}{c}21(91.3) \\
2(8.7)\end{array}$ & 0.04 \\
\hline Midline shift $\geq 10 \mathrm{~mm}$ & $11(25)$ & $8(34.8)$ & 0.393 \\
\hline Hydrocephalus & $1(2.3)$ & 0 & $>0.99$ \\
\hline $\begin{array}{l}\text { Hospital course } \\
\text { Surgical intervention } \\
\text { ICP monitor/EVD }\end{array}$ & $\begin{array}{l}24(54.6) \\
24(54.6)\end{array}$ & $\begin{array}{l}20(87.0) \\
18(78.3)\end{array}$ & 0.014 \\
\hline
\end{tabular}

$\mathrm{EVD}=$ external ventricular drain.

${ }^{*}$ Values are number of patients (\%).

chance of eventually attaining a GOS score of 5 or normal. There was a $40 \%$ and $33 \%$ chance of attaining GOS scores of 4 and 1-3, respectively. The chance for patients with an abnormal pupillary response to attain GOS scores of $1-3,4$, or 5 were $92 \%, 8 \%$, and $0 \%$.

In patients with a normal pupillary response, the next classification branch point was based on the mechanism of injury. Patients injured in a fall did well, with $100 \%$ attaining a long-term outcome of normal or GOS score of 5. In patients with a different mechanism of injury, the evaluation of the fontanelle (if present) was the next variable.
TABLE 3. Outcomes at discharge using the modified GOS $(n=67)$

\begin{tabular}{|c|c|c|c|}
\hline GOS & GCS Score $3^{*}(n=44)$ & GCS Score $4^{*}(n=23)$ & $\mathrm{p}$ Value \\
\hline Normal & 0 & 0 & $0.447 \dagger$ \\
\hline 5 & $2(4.6)$ & $2(8.7)$ & \\
\hline 4 & $7(15.9)$ & $3(13.0)$ & \\
\hline 3 & $5(11.4)$ & $4(17.4)$ & \\
\hline 2 & $3(6.8)$ & 4 (17.4) & \\
\hline 1 & $27(61.4)$ & $10(43.5)$ & $0.2 \ddagger$ \\
\hline
\end{tabular}

* Values are number of patients (\%).

$\dagger$ No statistically significant difference in discharge GOS scores.

$\ddagger$ No statistically significant difference in survival.

In patients with abnormal pupillary response, hypothermia was the next most predictive of outcome. One hundred percent of the patients with an abnormal pupillary response and hypothermia had a GOS score of 1-3.

\section{Discussion}

A physician may be faced with complex medical and ethical challenges in the care of the most severely injured TBI patients. Patients presenting with low postresuscitation GCS scores have extremely high morbidity and mortality rates. ${ }^{14,18,29,50}$

\section{Predictive Variables for Survival}

In general, survival of critically ill patients has improved with advanced prehospital, emergency, and intensive care techniques. ${ }^{35,52}$ There are papers discussing survival in severely head-injured adults. Chamoun et al. reported survival in $50.8 \%$ of adult TBI patients presenting with a GCS score of 3 and good outcome at 6 months in $13.2 \%$. The factors most predictive of outcome were age, ICP, and pupil reactivity at admission. ${ }^{8}$ Tien et al. reported an overall mortality rate of $76.8 \%$ in 173 patients with GCS score of 3; the mortality was $100 \%$ in patients with fixed, dilated pupils and $42 \%$ in patients with reactive pupils. ${ }^{50}$ Other studies in adults show relatively consistent factors that correlate with survival and, conversely, death. Factors that are associated with poor survival include hypoxia, extremes of age, hypotension, hypercarbia, hyperglycemia, mechanism of injury, and hypothermia. ${ }^{6,21,25,28,36,39,43,51,53}$ Other factors that may be independent predictors of outcome in severe TBI patients include prehospital deterioration, duration of coma, time to "follow commands" duration of amnesia, time to resume oral feeding, and measurement of the efficacy of interventions designed to lower ICP. . $^{17,20,40,45}$

As most of the published studies evaluated adults, we sought to examine a relatively large cohort of children presenting with a postresuscitation GCS (modified for pediatric patients) score of 3 or 4 . We evaluated 67 children treated at a Level 1 trauma center. The demographics of the patient population are shown in Table 1. This table presents the comparison of 44 patients with a GCS score of 3 and 23 patients with a GCS score of 4 . There were no statistically significant differences in the demographics between the 2 groups. There were minor differences in certain variables at presentation (Table 2). Patients with GCS score of 3 were more likely to be hypoxic (65.9\% vs $39.1 \%$; $\mathrm{p}=0.046$ ), less likely to have open basilar cis- 


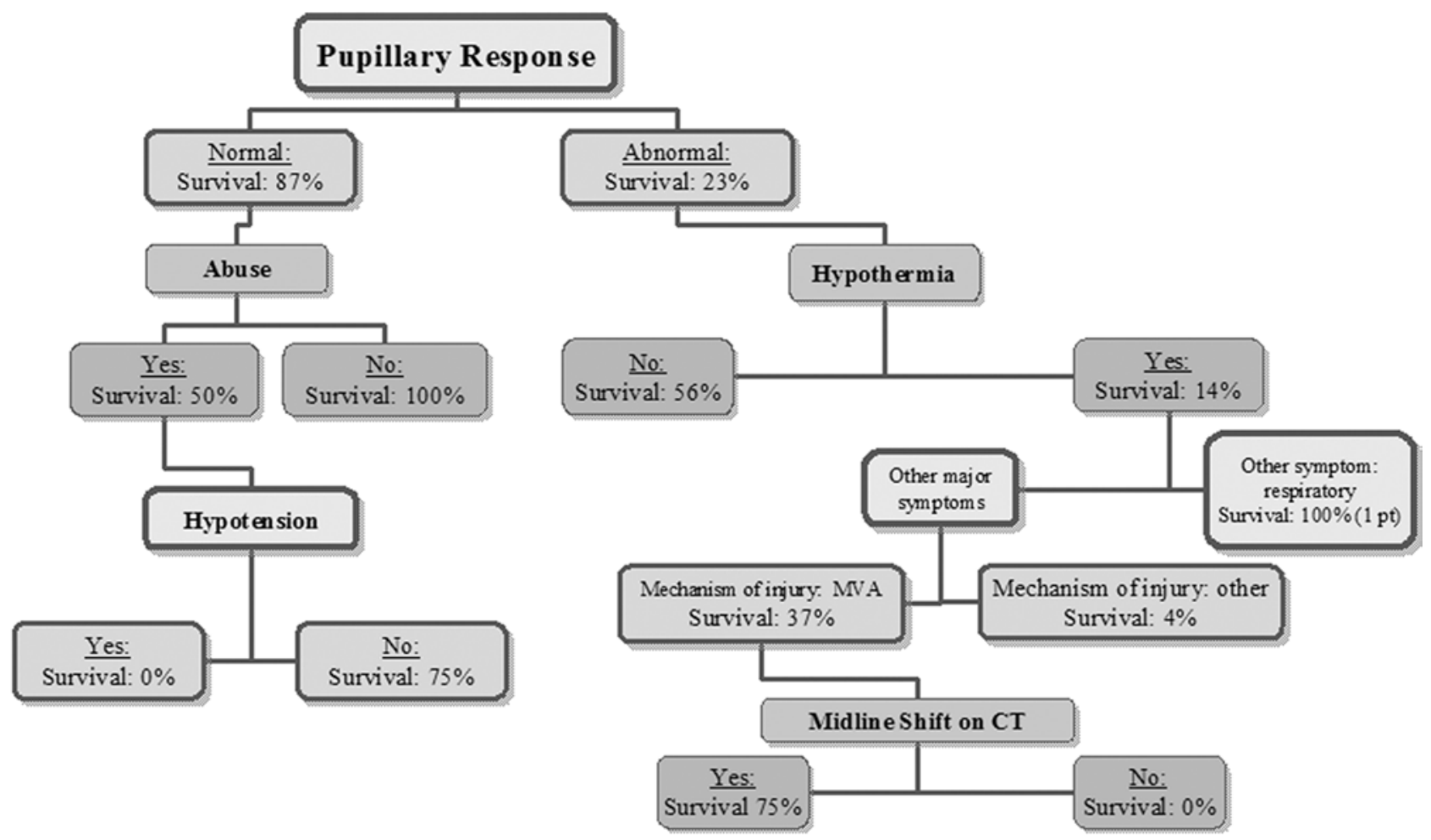

FIG. 1. Classification tree for predictive variables correlated with survival. MVA = motor vehicle accident; $p t=$ patient.

terns $(68.2 \%$ vs $91.3 \% ; \mathrm{p}=0.04)$, and less likely to have single seizure $(2.3 \%$ vs $17.4 \%$; $\mathrm{p}=0.044)$. Patients with GCS 4 were more likely to receive surgical intervention ( $p$ $=0.014)$. The outcomes at discharge, based on a modified GOS, are shown in Table 3. Overall, 37 patients (55.2\%) died. The survival and clinical outcome at discharge were statistically similar between the GCS 3 and 4 patients. We therefore combined the patients to analyze predictive variables for survival and clinical outcome.

Figure 1 shows a statistical classification tree that stratifies the chance of survival based on predictor variables. The variable with the highest correlation to survival was the pupillary reaction. If the pupillary reaction was abnormal in one or both eyes, the probability of survival was $23 \%$. Conversely, if the pupils were both normally reactive, the chance of survival was $87 \%$. The next predictor in children with reactive pupils was the presence of abuse. Children with reactive pupils in whom the mechanism of injury was abuse had a $50 \%$ chance of survival. Children with reactive pupils and no history of abuse had $100 \%$ survival (17 survivors, 0 deaths).

In the patients with an abnormal pupillary examination, the next most important variable was the presence of hypothermia. Patients with an absent pupillary reflex and hypothermia had a $14 \%$ chance of survival, whereas those with an absent pupillary reflex and no hypothermia had a chance of survival of $56 \%$. Each subsequent branch point gives the outcome of the sequence of variables. For example, a child with an absent pupillary reflex, with hypothermia, with a mechanism of action other than motor vehicle accident, and over 3 months of age had a $0 \%$ survival (23 deaths).

\section{Predictive Variables for Clinical Outcome}

Clinicians may justifiably argue that clinical outcomes are more relevant than survival. One may question the utility of therapy that allows survival but leaves the patient in a vegetative state. There are very few data regarding the long-term outcomes in severely injured children.

In our cohort, 29 (43.3\%) of 67 patients survived to 1 year. We were able to obtain data regarding long-term clinical outcome in 22 of the survivors. The long-term GOS score was the same as the 1-year GOS score in 21 (95.5\%) of 22 patients, with 1 patient improving from a score of 2 to a score of 3 . Previously published papers indicate that the GOS score at discharge and at 3 months predict the outcomes at 1 year. ${ }^{26,30,31}$ There are few reported studies that have followed patients for longer than 1 year. For those studies that evaluated patients for longer

TABLE 4. Patient outcomes at 1 year $(n=67)$

\begin{tabular}{lc}
\hline \multicolumn{1}{c}{ Outcome } & No. of Patients $(\%)$ \\
\hline Died & $38(56.7)^{*}$ \\
\hline Survivors & $29(43.3)$ \\
\hline GOS score & \\
\hline Normal & $8(11.9)$ \\
5, good & $2(3.0)$ \\
4, disabled & $4(6.0)$ \\
3, severely disabled & $7(10.4)$ \\
2, vegetative & $3(4.5)$ \\
Unknown (lost to follow-up) & $5(7.5)$ \\
\hline
\end{tabular}

* Includes 1 patient who survived to discharge but died prior to 1-year follow-up. 
TABLE 5. Long-term follow-up in survivors with initial GCS scores of 3 or 4

\begin{tabular}{|c|c|c|c|c|c|c|c|}
\hline \multirow{2}{*}{$\begin{array}{l}\text { GCS Score } \\
\& \text { Case No. }\end{array}$} & \multirow{2}{*}{$\begin{array}{l}\text { Age at } \\
\text { Injury }\end{array}$} & \multirow[b]{2}{*}{ Mechanism } & \multicolumn{3}{|c|}{ GOS Score } & \multirow{2}{*}{$\begin{array}{l}\text { Follow-Up } \\
\text { Duration (yrs) }\end{array}$} & \multirow[b]{2}{*}{ Long-Term Clinical Notes } \\
\hline & & & Discharge & $1 \mathrm{Yr}$ & Long Term & & \\
\hline \multicolumn{8}{|l|}{ GCS 3} \\
\hline 1 & $5 \mathrm{mos}$ & Fall & 5 & Normal & & & No follow-up after $1 \mathrm{yr}$ \\
\hline 2 & $4.6 \mathrm{yrs}$ & MVA/pedestrian & 5 & Normal & Normal & 23 & Fully functional \& lives independently \\
\hline 3 & 10.3 yrs & MVA/passenger & 4 & Normal & Normal & 23 & $\begin{array}{l}\text { Gainfully employed, lives independently, fully } \\
\text { functional }\end{array}$ \\
\hline 4 & $2.3 \mathrm{yrs}$ & Fall & 4 & Unknown & & & \\
\hline 5 & $1 \mathrm{mo}$ & NAT & 2 & 2 & 2 & 3 & $\begin{array}{l}\text { Cortical blindness, spastic quadriparesis, } \\
\text { vegetative }\end{array}$ \\
\hline 6 & $14.5 \mathrm{yrs}$ & MVA/pedestrian & 3 & Normal & Normal & & Neurologically intact \\
\hline 7 & 2 mos & NAT & 3 & 3 & 3 & 16 & Nonverbal, spastic quadriparesis \\
\hline 8 & $2.5 \mathrm{yrs}$ & NAT & 4 & 2 & 2 & 3 & Vegetative \\
\hline 9 & $5.6 \mathrm{yrs}$ & MVA/pedestrian & 4 & 5 & 5 & 16 & $\begin{array}{l}\text { Required special education classes for delay, } \\
\text { unemployed }\end{array}$ \\
\hline 10 & $1 \mathrm{mo}$ & NAT & 3 & 3 & 3 & 10 & Nonverbal, spastic quadriparesis \\
\hline 11 & $3 \mathrm{mos}$ & NAT & 3 & 3 & 3 & 5 & Seizures, severe developmental delay \\
\hline 12 & 1.4 yrs & NAT & 4 & Unknown & & & \\
\hline 13 & 2 mos & NAT & 2 & Normal & Normal & 10 & Neurologically normal \\
\hline 14 & $1.9 \mathrm{yrs}$ & MVA/passenger & 2 & 1 & & & Survived to discharge, but died prior to $1 \mathrm{yr}$ \\
\hline 15 & $15.1 \mathrm{yrs}$ & MVA/passenger & 3 & 3 & 3 & 13 & Spasticity, mental retardation \\
\hline 16 & $3.3 \mathrm{yrs}$ & NAT & 4 & Unknown & & & \\
\hline 17 & 13.6 yrs & MVA/bicycle struck & 4 & 5 & 5 & 10 & $\begin{array}{l}\text { Graduated high school, some behavior problems, } \\
\text { receives disability, memory problems, lives w/ } \\
\text { family }\end{array}$ \\
\hline \multicolumn{8}{|l|}{ GCS 4} \\
\hline 1 & $5.5 \mathrm{yrs}$ & MVA/pedestrian & 3 & 3 & 3 & 3 & Spasticity, severe delay \\
\hline 2 & $1.8 \mathrm{yrs}$ & MVA/pedestrian & 3 & 3 & 3 & 4 & Spasticity, severe delay \\
\hline 3 & $8.3 \mathrm{yrs}$ & MVA/passenger & 2 & 2 & 2 & 13 & $\begin{array}{l}\text { Eyes open, will look around, nonverbal, requires } \\
\text { full-time care }\end{array}$ \\
\hline 4 & $2.5 \mathrm{yrs}$ & MVA/pedestrian & 4 & 4 & 4 & 20 & $\begin{array}{l}\text { Seizure disorder, moderate mental delay, lives } \\
\text { w/ parents, not employed }\end{array}$ \\
\hline 5 & $5.9 \mathrm{yrs}$ & Fall & 5 & Normal & Normal & 5 & Neurologically normal \\
\hline 6 & $14.2 \mathrm{yrs}$ & MVA/bicycle struck & 2 & Unknown & & & \\
\hline 7 & $2 \mathrm{mos}$ & NAT & 2 & 2 & 3 & 7 & Spastic quadriplegia, mental retardation \\
\hline 8 & 15.7 yrs & Struck by object & 2 & 5 & 5 & 14 & $\begin{array}{l}\text { Graduated high school, on disability, lives in- } \\
\text { dependently }\end{array}$ \\
\hline 9 & $6.1 \mathrm{yrs}$ & Fall & 5 & Normal & Normal & 13 & $\begin{array}{l}\text { "A" student in honors classes, neurologically } \\
\text { normal }\end{array}$ \\
\hline 10 & $8.4 \mathrm{yrs}$ & MVA/passenger & 3 & Normal & Normal & 11 & $\begin{array}{l}\text { Graduated high school, in college classes \& em- } \\
\text { ployed in day care, chronic headaches }\end{array}$ \\
\hline 11 & $2.6 \mathrm{yrs}$ & MVA/pedestrian & 4 & 4 & 4 & 10 & $\begin{array}{l}\text { Special education classes, plays basketball, } \\
\text { aggressive behavior in school }\end{array}$ \\
\hline 12 & 7.9 yrs & MVA/pedestrian & 3 & 4 & 4 & 11 & $\begin{array}{l}\text { Attends high school \& scheduled to graduate w/ } \\
\text { a certificate at age } 21 \text {, seizures, developmen- } \\
\text { tal delay }\end{array}$ \\
\hline 13 & $1.3 \mathrm{yrs}$ & NAT & 4 & Unknown & & & \\
\hline
\end{tabular}

MVA = motor vehicle accident; NAT = nonaccidental trauma.

than 1 year, clinical improvement was frequently reported months after severe TBI in adult patients.., 26

There are a number of differences between a pediatric and an adult TBI patient. Many abuse patients are injured at a very early age, when the developing brain may be particularly vulnerable. ${ }^{37}$ Children have changing needs as they grow and are dependent on their environment and social situation. Indeed, preinjury factors, such as education 


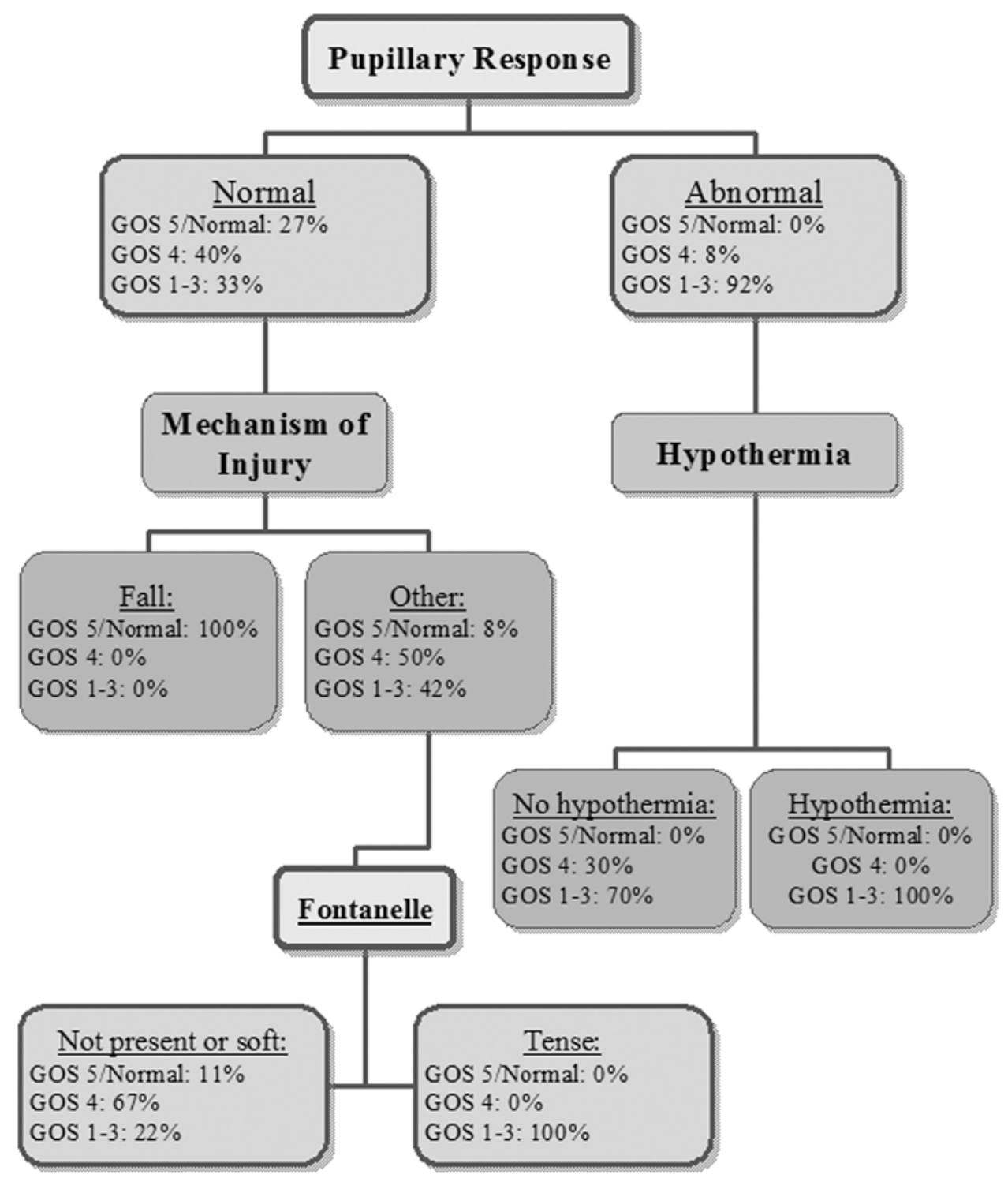

FIG. 2. Classification tree for predictive variables correlated with outcome.

level and age, influence recovery after TBI. ${ }^{13,24,33,34,41}$ Pediatric TBI patients may have prolonged impairment, demonstrated by poor school performance, poor quality of life measures, need for special education services, and mental health problems..$^{3,15-17}$ Rivara et al. compared a cohort of children with head injury with a control group of children with orthopedic injuries. ${ }^{38}$ Children with head injury required higher levels of community resources than the control group despite a similar overall severity of injury. At 24 months, the health-related quality of life of patients with moderate or severe TBI continued to be worse than baseline. Notably, there was improvement over the first 2 years after injury. ${ }^{36}$ Arnett et al. studied the educational outcome in children with mild, moderate, or severe TBI 1 year after brain injury. ${ }^{3}$ Outcome was correlated with postinjury executive functioning ability (including attention control, inhibition, organization, planning, and self-monitoring) independent of the severity of the initial injury. ${ }^{3}$ In one of the few studies following children longer than 1 year, An- derson et al. evaluated predictors of cognitive function 10 years after TBI in a cohort of 40 children. ${ }^{2}$ The preinjury function and family status was correlated with long-term outcomes. Environmental factors contributed to recovery and patients made progress up to 10 years after injury. ${ }^{2}$ Access to rehabilitation facilities may improve long-term outcomes. ${ }^{48}$

The clinical outcomes at 1 year in our patients are shown in Table 4. Ten patients (14.9\%) were either "normal" or had a GOS score of 5 at 1 year. Long-term outcome data were obtained for 22 patients with a mean of $11.04 \pm 6.1$ years (median 10.5 years) of clinical follow-up. Ten of 22 patients with long-term data had a GOS score of 5 or "normal" outcome.

A second classification tree (Fig. 2) was generated based on the presenting variables and the long-term outcomes. As with survival, the pupillary response was the factor most correlated with outcome. This is consistent with other published studies. ${ }^{8,26,50}$ In patients with an absent pupil- 
lary response, the next most correlative predictive variable in our study was the presence of hypothermia.

Note that we did not therapeutically induce hypothermia in any patient. In our cohort, hypothermia likely was caused by either prolonged extrication or a loss of cerebral autoregulation. Therapeutic hypothermia continues to generate interest as a potential treatment for head injury, despite multiple studies that do not demonstrate benefit. ${ }^{1,11,22}$ Our data argue against the concept of hypothermia as a protective element. Patients with an absent pupillary reflex and hypothermia had a $0 \%$ chance of an outcome of "normal," GOS score of 5, or GOS score of 4.

Note that all variables (clinical, epidemiological, and radiological) were analyzed for creation of the classification trees. Prior to the analysis, we intuitively believed that certain variables would predict survival and good outcome. We thought that the presence of an operable epidural hematoma or a single seizure (with the postictal state clouding the initial examination) would predict a good outcome. Interestingly, neither of these factors were the most predictive of survival or outcome. "Midline shift" was correlated with survival but was low on the classification tree (Fig. 1).

\section{Study Limitations}

One of the difficulties in evaluating trauma patients is the heterogeneity of the population and treatments. Treatment of TBI patients at Riley is currently based on the accepted evidence-based guidelines. ${ }^{5}$ However, the initial data were largely obtained prior to publication of widely accepted pediatric trauma guidelines. We adhered to principles of preventing hypoxia, preventing hypotension, monitoring ICP in selected patients, and surgically evacuating mass lesions. Patients with presumed hypoxic injury from nonaccidental trauma were supported, but were generally not treated surgically. We did not actively cool patients for therapeutic hypothermia. Even with consensus trauma guidelines, there is a significant need for individual physician judgment and, by necessity, heterogeneity in care.

The database was initially created in 1988. Since its creation, a number of outcome scales have been developed that improve on the original GOS. There are now validated outcome scales specific for children, including the Glasgow Outcome Scale-Extended (GOS-E), the GOS-E Pediatric Revision, and the Pediatric Cerebral Performance Scale (PCPS).,19,23 These scales account for pediatric-specific issues, such as needs at various stages of development. We acknowledge that the pediatric outcomes are better assessed by these tools than the rather broad GOS; however, we chose to remain consistent in our analysis of the original data. We did use a modified GCS for pediatric patients. A number of other evaluation scores have been developed that may be more specific to pediatric patients than the $\mathrm{GCS} .^{12}$

\section{Conclusions}

Children with severe TBI and a presenting GCS score of 3 or 4 have a high likelihood of death and morbidity. In our analysis, $48(71.6 \%)$ of 67 patients either died, were severely disabled, or were vegetative. However, $14.9 \%$ of patients had a good outcome. Factors that were associated with poor survival and poor outcome included an abnormal pupillary response, hypothermia, and the presence of abuse.

Our results provide some guidance for decision making in cases involving these critically injured children. The chances of meaningful survival in a patient with an abnormal pupillary response and hypothermia are extremely low. The clinician may decide that aggressive therapy in these patients is not warranted. Conversely, children with normal pupillary responses who were injured by a mechanism other than abuse may have a good or even normal outcome despite a GCS score of 3 or 4 . While standard guidelines are necessary in the management of head-injured patients, critical decisions must be individualized.

\section{Acknowledgments}

The authors would like to thank the Goodman Campbell Foundation and the Department of Biostatistics, Richard M. Fairbanks School of Public Health (George J. Eckert and Fei He) for statistical analysis.

\section{References}

1. Adelson PD, Wisniewski SR, Beca J, Brown SD, Bell M, Muizelaar JP, et al: Comparison of hypothermia and normothermia after severe traumatic brain injury in children (Cool Kids): a phase 3, randomised controlled trial. Lancet Neurol 12:546-553, 2013

2. Anderson V, Godfrey C, Rosenfeld JV, Catroppa C: Predictors of cognitive function and recovery 10 years after traumatic brain injury in young children. Pediatrics 129:e254e261, 2012

3. Arnett AB, Peterson RL, Kirkwood MW, Taylor HG, Stancin T, Brown TM, et al: Behavioral and cognitive predictors of educational outcomes in pediatric traumatic brain injury. $\mathbf{J}$ Int Neuropsychol Soc 19:881-889, 2013

4. Beers SR, Wisniewski SR, Garcia-Filion P, Tian Y, Hahner T, Berger RP, et al: Validity of a pediatric version of the Glasgow Outcome Scale-Extended. J Neurotrauma 29:1126-1139, 2012

5. Brain Trauma Foundation: Guidelines for the management of severe traumatic brain injury. J Neurotrauma 24 (Suppl 1):S1-S106, 2007

6. Brazinova A, Mauritz W, Leitgeb J, Wilbacher I, Majdan M, Janciak I, et al: Outcomes of patients with severe traumatic brain injury who have Glasgow Coma Scale scores of 3 or 4 and are over 65 years old. J Neurotrauma 27:1549-1555, 2010

7. Breiman L, Friedman JH, Olshen RA, Stone CJ: Classification and Regression Trees. New York: Chapman and Hall/ CRC, 1984

8. Chamoun RB, Robertson CS, Gopinath SP: Outcome in patients with blunt head trauma and a Glasgow Coma Scale score of 3 at presentation. J Neurosurg 111:683-687, 2009

9. Choi SC, Barnes TY, Bullock R, Germanson TA, Marmarou A, Young HF: Temporal profile of outcomes in severe head injury. J Neurosurg 81:169-173, 1994

10. Chung CY, Chen CL, Cheng PT, See LC, Tang SF, Wong AM: Critical score of Glasgow Coma Scale for pediatric traumatic brain injury. Pediatr Neurol 34:379-387, 2006

11. Clifton GL, Miller ER, Choi SC, Levin HS, McCauley S, Smith KR Jr, et al: Lack of effect of induction of hypothermia after acute brain injury. N Engl J Med 344:556-563, 2001

12. Cuff S, DiRusso S, Sullivan T, Risucci D, Nealon P, Haider A, et al: Validation of a relative head injury severity scale for pediatric trauma. J Trauma 63:172-178, 2007 
13. de Oliveira Thais ME, Cavallazzi G, Formolo DA, de Castro LD, Schmoeller R, Guarnieri R, et al: Limited predictive power of hospitalization variables for long-term cognitive prognosis in adult patients with severe traumatic brain injury. J Neuropsychol 8:125-139, 2014

14. Demetriades D, Kuncir E, Velmahos GC, Rhee P, Alo K, Chan LS: Outcome and prognostic factors in head injuries with an admission Glasgow Coma Scale score of 3. Arch Surg 139:1066-1068, 2004

15. Di Battista A, Soo C, Catroppa C, Anderson V: Quality of life in children and adolescents post-TBI: a systematic review and meta-analysis. J Neurotrauma 29:1717-1727, 2012

16. Ewing-Cobbs L, Fletcher JM, Levin HS, Iovino I, Miner ME: Academic achievement and academic placement following traumatic brain injury in children and adolescents: a two-year longitudinal study. J Clin Exp Neuropsychol 20:769-781, 1998

17. Farahvar A, Gerber LM, Chiu YL, Härtl R, Froelich M, Carney N, et al: Response to intracranial hypertension treatment as a predictor of death in patients with severe traumatic brain injury. J Neurosurg 114:1471-1478, 2011 (Erratum in J Neurosurg 115:191)

18. Fearnside MR, Cook RJ, McDougall P, McNeil RJ: The Westmead Head Injury Project outcome in severe head injury. A comparative analysis of pre-hospital, clinical and CT variables. Br J Neurosurg 7:267-279, 1993

19. Fiser DH, Long N, Roberson PK, Hefley G, Zolten K, BrodieFowler M: Relationship of pediatric overall performance category and pediatric cerebral performance category scores at pediatric intensive care unit discharge with outcome measures collected at hospital discharge and 1- and 6-month follow-up assessments. Crit Care Med 28:2616-2620, 2000

20. Formisano R, Carlesimo GA, Sabbadini M, Loasses A, Penta F, Vinicola V, et al: Clinical predictors and neuropsychological outcome in severe traumatic brain injury patients. Acta Neurochir (Wien) 146:457-462, 2004

21. Haider AH, Crompton JG, Oyetunji T, Risucci D, DiRusso $\mathrm{S}$, Basdag $\mathrm{H}$, et al: Mechanism of injury predicts case fatality and functional outcomes in pediatric trauma patients: the case for its use in trauma outcomes studies. J Pediatr Surg 46:1557-1563, 2011

22. Hutchison JS, Ward RE, Lacroix J, Hébert PC, Barnes MA, Bohn DJ, et al: Hypothermia therapy after traumatic brain injury in children. N Engl J Med 358:2447-2456, 2008

23. Jennett B, Snoek J, Bond MR, Brooks N: Disability after severe head injury: observations on the use of the Glasgow Outcome Scale. J Neurol Neurosurg Psychiatry 44:285293, 1981

24. Jeon IC, Kim OL, Kim MS, Kim SH, Chang CH, Bai DS: The effect of premorbid demographic factors on the recovery of neurocognitive function in traumatic brain injury patients. J Korean Neurosurg Soc 44:295-302, 2008

25. Kilaru S, Garb J, Emhoff T, Fiallo V, Simon B, Swiencicki $\mathrm{T}$, et al: Long-term functional status and mortality of elderly patients with severe closed head injuries. J Trauma 41:957963, 1996

26. King JT Jr, Carlier PM, Marion DW: Early Glasgow Outcome Scale scores predict long-term functional outcome in patients with severe traumatic brain injury. J Neurotrauma 22:947-954, 2005

27. Kirkham FJ, Newton CR, Whitehouse W: Paediatric coma scales. Dev Med Child Neurol 50:267-274, 2008

28. Koç RK, Akdemir H, Oktem IS, Meral M, Menkü A: Acute subdural hematoma: outcome and outcome prediction. Neurosurg Rev 20:239-244, 1997

29. Kotwica Z, Jakubowski JK: Head-injured adult patients with GCS of 3 on admission - who have a chance to survive? Acta Neurochir (Wien) 133:56-59, 1995

30. Kouloulas EJ, Papadeas AG, Michail X, Sakas DE, Boviatsis
EJ: Prognostic value of time-related Glasgow coma scale components in severe traumatic brain injury: a prospective evaluation with respect to 1-year survival and functional outcome. Int J Rehabil Res 36:260-267, 2013

31. Leitgeb J, Mauritz W, Brazinova A, Majdan M, Janciak I, Wilbacher I, et al: Glasgow Coma Scale score at intensive care unit discharge predicts the 1-year outcome of patients with severe traumatic brain injury. Eur J Trauma Emerg Surg 39:285-292, 2013

32. Luerssen TG: Central Nervous System Injuries, in O'Neil J, Rowe MI, Grosfeld JL, Fonkalsrud EW, Coran AC (eds): Pediatric Surgery, ed 5th. St. Louis: Mosby Inc., 1998

33. Marmarou A, Lu J, Butcher I, McHugh GS, Mushkudiani NA, Murray GD, et al: IMPACT database of traumatic brain injury: design and description. J Neurotrauma 24:239-250, 2007

34. Mushkudiani NA, Engel DC, Steyerberg EW, Butcher I, Lu J, Marmarou A, et al: Prognostic value of demographic characteristics in traumatic brain injury: results from the IMPACT study. J Neurotrauma 24:259-269, 2007

35. Pineda JA, Leonard JR, Mazotas IG, Noetzel M, Limbrick DD, Keller MS, et al: Effect of implementation of a paediatric neurocritical care programme on outcomes after severe traumatic brain injury: a retrospective cohort study. Lancet Neurol 12:45-52, 2013

36. Ramaiah VK, Sharma D, Ma L, Prathep S, Hoffman NG, Vavilala MS: Admission oxygenation and ventilation parameters associated with discharge survival in severe pediatric traumatic brain injury. Childs Nerv Syst 29:629-634, 2013

37. Rivara FP, Koepsell TD, Wang J, Temkin N, Dorsch A, Vavilala MS, et al: Disability 3, 12, and 24 months after traumatic brain injury among children and adolescents. Pediatrics 128:e1129-e1138, 2011

38. Rivara FP, Koepsell TD, Wang J, Temkin N, Dorsch A, Vavilala MS, et al: Incidence of disability among children 12 months after traumatic brain injury. Am J Public Health 102:2074-2079, 2012

39. Saadat S, Akbari H, Khorramirouz R, Mofid R, RahimiMovaghar V: Determinants of mortality in patients with traumatic brain injury. Ulus Travma Acil Cerrahi Derg 18:219-224, 2012

40. Sandhaug M, Andelic N, Vatne A, Seiler S, Mygland A: Functional level during sub-acute rehabilitation after traumatic brain injury: course and predictors of outcome. Brain Inj 24:740-747, 2010

41. Sherrill-Pattison S, Donders J, Thompson E: Influence of demographic variables on neuropsychological test performance after traumatic brain injury. Clin Neuropsychol 14:496-503, 2000

42. Simpson D, Reilly P: Pediatric coma scale. Lancet 2:450, 1982

43. Smith RL, Lin JC, Adelson PD, Kochanek PM, Fink EL, Wisniewski SR, et al: Relationship between hyperglycemia and outcome in children with severe traumatic brain injury. Pediatr Crit Care Med 13:85-91, 2012

44. Sosin DM, Sniezek JE, Waxweiler RJ: Trends in death associated with traumatic brain injury, 1979 through 1992. Success and failure. JAMA 273:1778-1780, 1995

45. Suskauer SJ, Slomine BS, Inscore AB, Lewelt AJ, Kirk JW, Salorio CF: Injury severity variables as predictors of WeeFIM scores in pediatric TBI: Time to follow commands is best. J Pediatr Rehabil Med 2:297-307, 2009

46. Tatman A, Warren A, Williams A, Powell JE, Whitehouse W: Development of a modified paediatric coma scale in intensive care clinical practice. Arch Dis Child 77:519-521, 1997

47. Teasdale G, Maas A, Lecky F, Manley G, Stocchetti N, Murray G: The Glasgow Coma Scale at 40 years: standing the test of time. Lancet Neurol 13:844-854, 2014 
48. Tepas JJ III, Leaphart CL, Pieper P, Beaulieu CL, Spierre LR, Tuten JD, et al: The effect of delay in rehabilitation on outcome of severe traumatic brain injury. J Pediatr Surg 44:368-372, 2009

49. Thurman DJ, Alverson C, Dunn KA, Guerrero J, Sniezek JE: Traumatic brain injury in the United States: A public health perspective. J Head Trauma Rehabil 14:602-615, 1999

50. Tien HC, Cunha JR, Wu SN, Chughtai T, Tremblay LN, Brenneman FD, et al: Do trauma patients with a Glasgow Coma Scale score of 3 and bilateral fixed and dilated pupils have any chance of survival? J Trauma 60:274-278, 2006

51. Tude Melo JR, Di Rocco F, Blanot S, Oliveira-Filho J, Roujeau T, Sainte-Rose C, et al: Mortality in children with severe head trauma: predictive factors and proposal for a new predictive scale. Neurosurgery 67:1542-1547, 2010

52. Vavilala MS, Kernic MA, Wang J, Kannan N, Mink RB, Wainwright MS, et al: Acute care clinical indicators associated with discharge outcomes in children with severe traumatic brain injury. Crit Care Med 42:2258-2266, 2014

53. Wells R, Minnes P, Phillips M: Predicting social and func- tional outcomes for individuals sustaining paediatric traumatic brain injury. Dev Neurorehabil 12:12-23, 2009

\section{Author Contributions}

Conception and design: Fulkerson, White. Acquisition of data: Fulkerson, Rees, Baumanis, Smith, Ackerman, Boaz, Luerssen. Analysis and interpretation of data: Fulkerson, White, Luerssen. Drafting the article: Fulkerson, White. Critically revising the article: Fulkerson, Smith, Ackerman, Boaz, Luerssen. Reviewed submitted version of manuscript: Fulkerson. Approved the final version of the manuscript on behalf of all authors: Fulkerson. Study supervision: Fulkerson.

\section{Correspondence}

Daniel H. Fulkerson, Indiana University School of Medicine/ Goodman Campbell Brain and Spine, Riley Hospital for Children, 702 Barnhill Dr. \#1134, Indianapolis, IN 46202-5200. email: dfulkers@iupui.edu. 